\title{
ENSO regimes: Reinterpreting the canonical and Modoki El Niño
}

\author{
K. Takahashi, ${ }^{1}$ A. Montecinos, ${ }^{2}$ K. Goubanova, ${ }^{1,3}$ and B. Dewitte ${ }^{1,3}$ \\ Received 7 March 2011; revised 16 April 2011; accepted 19 April 2011; published 27 May 2011.
}

[1] We propose that the first two empirical orthogonal function (EOF) modes of tropical Pacific sea surface temperature (SST) anomalies do not describe different phenomena (i.e., El Niño-Southern Oscillation (ENSO) and "El Niño Modoki") but rather the nonlinear evolution of ENSO. We introduce two new uncorrelated indices $(E$ and $C$ ), based on the leading EOFs, that respectively account for extreme warm events in the eastern and cold/moderate warm events in the central equatorial Pacific, corresponding to regimes with different evolution. Recent trends in ENSO can be described as an increase in the central Pacific $(C)$ variability that is associated with stronger cold events, as well as a reduction in the eastern Pacific $(E)$ variability within the cold/moderate warm regime, consistent with model projections. However, little can be said observationally with respect to the extreme warm regime. Citation: Takahashi, K., A. Montecinos, K. Goubanova, and B. Dewitte (2011), ENSO regimes: Reinterpreting the canonical and Modoki El Niño, Geophys. Res. Lett., 38, L10704, doi:10.1029/2011GL047364.

\section{Introduction}

[2] It is well known that "no two El Niño events are quite alike" [Wyrtki, 1975], yet the typical evolution of such an event was thought to consist in an initial warming off South America and later in the central equatorial Pacific during austral summer (DJF) [Wyrtki, 1975; Rasmusson and Carpenter, 1982]. This belief changed with the extraordinary 1982-83 and 1997-98 El Niño events, which had large amplitudes and different evolutions with respect to the "canonical" composite [Cane, 1983], particularly as the maximum anomalies occurred simultaneously in the eastern and central equatorial Pacific during austral summer. This motivated descriptions of El Niño based on a single pattern and index (see discussion by Larkin and Harrison [2002]). Trenberth and Stepaniak [2001] proposed an additional index to regain the ability to describe the evolution of El Niño and its diversity of patterns (Trans-Niño Index or TNI).

[3] Recently, several studies argue for the existence of a different type of El Niño with SST anomalies concentrated in the central equatorial Pacific, [Larkin and Harrison, 2005; Ashok et al., 2007; Kug et al., 2009; Kao and Yu, 2009], even arguing that it is a phenomenon distinct from ENSO [Ashok et al., 2007], and there has been an increasing interest in determining the characteristics of its evolution, dynamics and

\footnotetext{
${ }^{1}$ Instituto Geofísico del Perú, Lima, Perú. Chile.

${ }^{2}$ Departamento de Geofísica, Universidad de Concepción, Concepción,

${ }^{3}$ Laboratoire d'Etudes en Géophysique et Océanographie Spatiale, CNES/CNRS/IRD/UPS, Toulouse, France.

Copyright 2011 by the American Geophysical Union. 0094-8276/11/2011GL047364
}

associated teleconnections [e.g., Weng et al., 2007; Kao and Yu, 2009; Kug et al., 2009; Yu and Kim, 2010].

[4] Furthermore, there is evidence that this type of El Niño has been more frequent during the last decades [Yeh et al., 2009; Lee and McPhaden, 2010]. Moreover, some climate models indicate an increase in the frequency of occurrence of this new El Niño under anthropogenic climate change [Yeh et al., 2009].

[5] The present study is aimed at providing a new interpretation of the various Niño indices and classifications and at improving our understanding of the relationship between the central Pacific type of El Niño, the "canonical" El Niño and the extraordinary events. In particular, we present evidence that suggests that these are all part of the same non-linear phenomenon rather than independent modes of variability.

\section{Data and Methodology}

[6] We calculated the EOF modes from monthly SST anomalies from the Hadley Centre Global Sea Ice and Sea Surface Temperature (HadISST) dataset version 1.1 [Rayner et al., 2003] in an equatorial Pacific domain, bounded by $10^{\circ} \mathrm{S}-10^{\circ} \mathrm{N}$ and the lateral coasts. We take $1979-2009$ as the base period for all climatologies, EOFs and correlations, approximately the same as Ashok et al. [2007]. We then projected the entire dataset (January 1870-August 2010) on the EOF patterns to obtain the principal components (PC) for this longer period. The PCs were normalized by the standard deviation for the base period and smoothed with a 1-2-1 filter. Dimensional spatial SST patterns were then obtained by linearly regressing the SST anomaly fields onto these PCs. Our domain is more confined to the equator than the one used by Ashok et al. [2007], as tests showed that it resulted in EOF modes that were less sensitive to the time domain considered.

[7] We performed a similar EOF decomposition on the SST data from three numerical climate models: 500 years from the pre-industrial unforced control run from the NOAA GFDL CM2.1 climate model [Wittenberg et al., 2006; Kug et al., 2010], a 1200-year run with Zebiak and Cane's [1987] intermediate coupled ocean-atmosphere model (ICM) for the tropical Pacific, and a 800-year run with the LODCA ICM [Dewitte and Gushchina, 2010] in which the ocean model described by Dewitte [2000] is coupled to the QTCM atmosphere model [Neelin and Zeng, 2000; Zeng et al., 2000]. These models are considered because they account for the diversity of physics and complexity for modeling the tropical Pacific interannual variability.

\section{Analysis and Results}

[8] The first two PCs combined explain most of the variance $(68 \%$ and $14 \%$, respectively) in the domain. Using multiple regression, we linearly combined the PCs to estimate the values of El Niño indices (traditional Niño indices [e.g., 


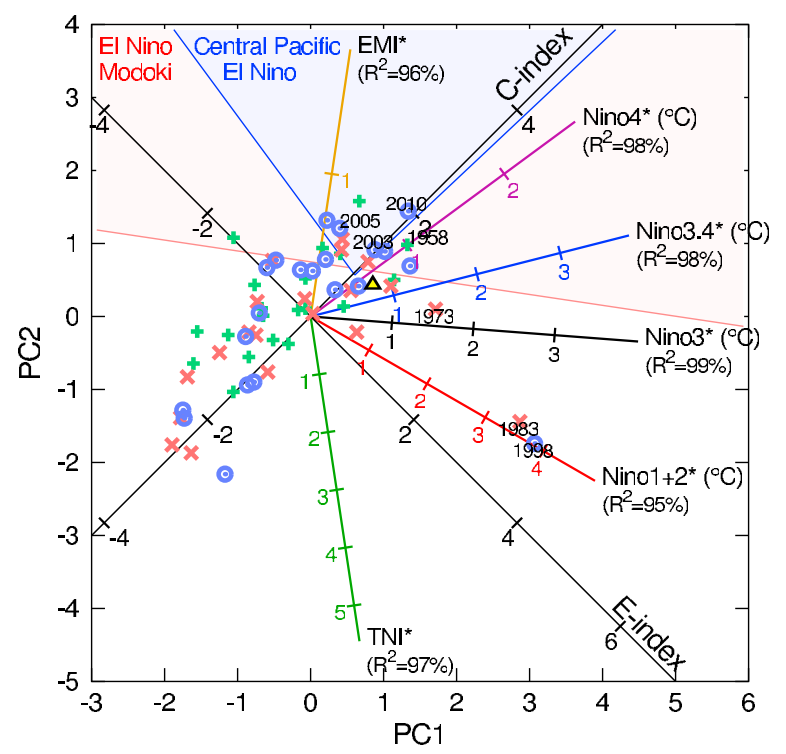

Figure 1. December-February (DJF) mean PC1 and PC2 from HadISST (period 1950-69: green plusses; 1970-89: red crosses; 1990-2010: blue circles; Rasmusson and Carpenter's [1982] composite is shown in a yellow triangle). Also shown are the axes corresponding to different multiple-regression estimates of Niño indices (variance explained indicated), as well as the $E$ and $C$ axes. The light-blue and light-red areas approximately correspond to $\mathrm{CP}$ events following $\mathrm{Yeh}$ et al. [2009] (i.e., Niño $3^{*}>0.5^{\circ} \mathrm{C}$ or Niño $4^{*}>0.5^{\circ} \mathrm{C}$, and Niño $4^{*}>$ Niño $3^{*}$ ) and Modoki events following Ashok et al. [2007] (i.e., EMI* $>0.7 \sigma$, where $\sigma$ is the standard deviation of 1979-2004 DJF-mean EMI*).

Trenberth and Stepaniak, 2001], the TNI [Trenberth and Stepaniak, 2001] and the El Niño Modoki Index (EMI) [Ashok et al., 2007]. For example, Niño $3.4^{*}=0.82 \mathrm{PC} 1+$ $0.21 \mathrm{PC} 2$, where $*$ denotes the estimate. As shown in Figure 1, each of such linear combinations corresponds to a rotation around the origin in the PC1-PC2 space. The coefficients of determination $\left(R^{2}\right)$ associated with these fits are very high $(95 \%$ or more), so hereafter we will make no explicit distinction between the actual indices and their estimates. The correlation coefficient between any two such indices is given by the cosine of the angle between the corresponding axes. For example, we verify that the TNI and EMI are significantly correlated, while Niño 3 and EMI are almost uncorrelated (Figure 1). Any given climate state corresponds to a point in the $\mathrm{PC} 1-\mathrm{PC} 2$ space and we can read the value for each of the Niño indices from the corresponding axis in Figure 1.

[9] The classification of events into Central Pacific [Yeh et al., 2009] or Modoki [Ashok et al., 2007] El Niño can be shown as regions in PC1-PC2 space (see caption of Figure 1 for the criteria used in both cases), and we see that neither reflects a preferential clustering of climate states (Figure 1), so from this perspective there is no evidence that they depict a new type of phenomenon separate from ENSO, as argued by Ashok et al. [2007]. Interestingly, the "canonical" El Niño composite [Rasmusson and Carpenter, 1982] is closer to the Modoki category than to the two extraordinary El Niño events of 1982-83 and 1997-98, while the "canonical" 1957 58 event clearly classifies as Modoki (Figure 1).
[10] On the other hand, from Figure 1 we can clearly identify two ENSO regimes: the regime of extraordinary warm events (the 1982-83 and 1997-98 events, as well as the 1877-78 event, not shown) and the regime that includes the cold, neutral, and moderately warm years. The states in the second regime are approximately located along a diagonal axis in the PC1-PC2 space, labelled as " $C$-index". For convenience, an orthogonal axis labelled " $E$-index" is included, which quantifies the departure from the $C$ axis. The corresponding indices are defined as:

$$
\begin{aligned}
& C=(\mathrm{PC} 1+\mathrm{PC} 2) / \sqrt{2}, \\
& E=(\mathrm{PC} 1-\mathrm{PC} 2) / \sqrt{2},
\end{aligned}
$$

which is equivalent to rotating the $\mathrm{PC} 1$ and $\mathrm{PC} 2$ axes by $45^{\circ}$. We can see, based on the angles between the axes in Figure 1, that $C$ and $E$ are well correlated with the central (Niño $4 ; R=$ 0.98 ) and eastern (Niño $1+2 ; R=0.94$ ) Pacific SST indices, respectively, and we can approximately calculate them as:

$$
\begin{gathered}
C \approx 1.7 \mathrm{Niño}_{4}-0.1 \mathrm{Niño}_{1+2}, \\
E \approx \mathrm{Niño}_{1+2}-0.5 \mathrm{Niño}_{4},
\end{gathered}
$$

with $R^{2}=98$ and $95 \%$, respectively.

[11] The two regimes are more clearly seen in monthly values for the October-March period (Figure 2a), which present a boomerang-shaped distribution. For the extraordinary regime $(\mathrm{PC} 1>2)$ the distribution is along the $E$ axis $(R=-0.65$ between $\mathrm{PC} 1$ and $\mathrm{PC} 2)$, but along the $C$ axis $(R=0.64)$ for the moderate $(\mathrm{PC} 1<2)$ regime. We emphasize that the selection of these axes obeys the directions preferred by the system, so the axes have dynamical meaning,
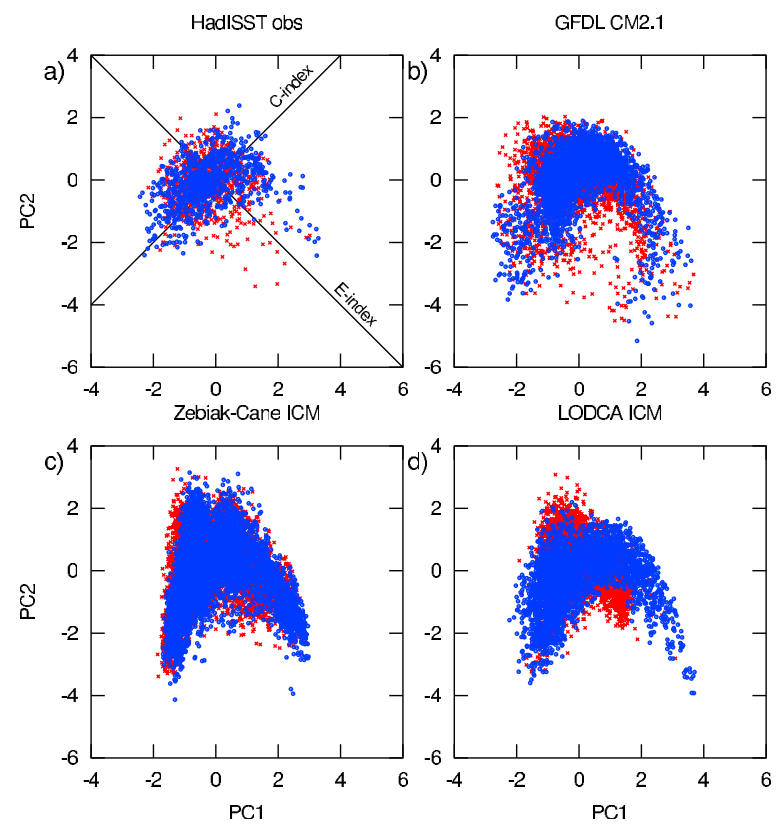

Figure 2. Monthly PC1 and PC2 (October-March: blue circles; April-September: red crosses) from (a) HadISST (1870-2010), (b) the GFDL CM2.1 climate model, and the (c) Zebiak-Cane and (d) LODCA intermediate coupled models. 

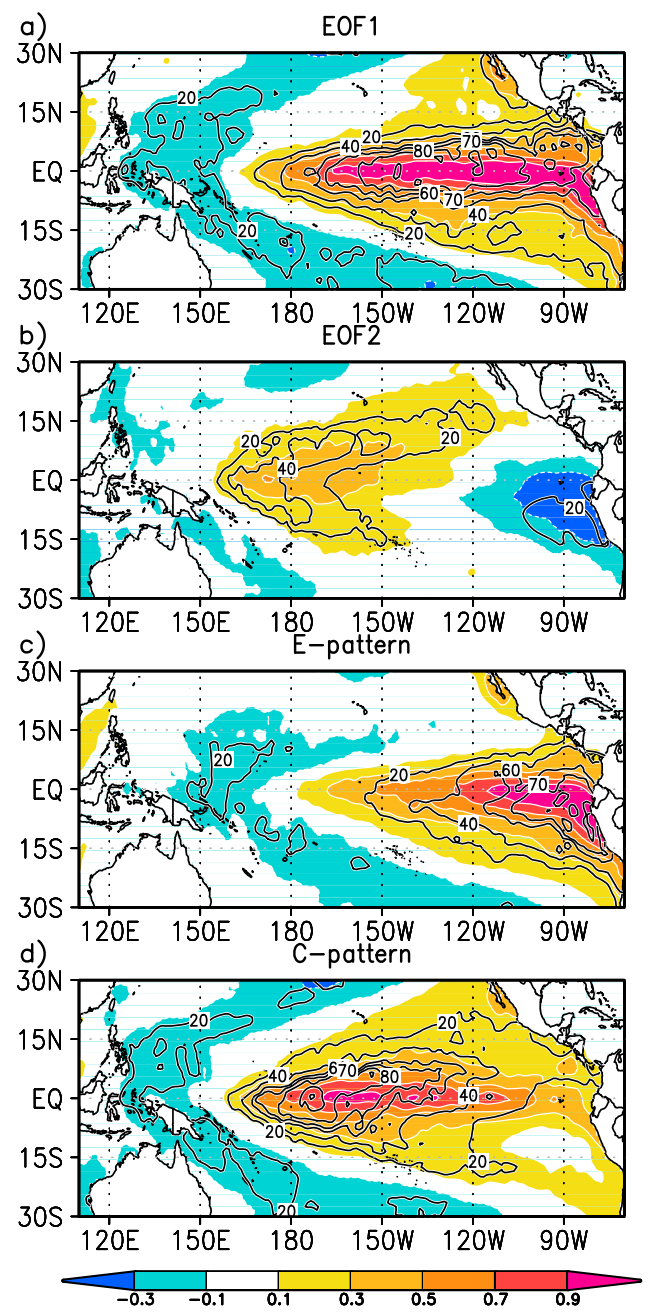

Figure 3. Linear regression coefficients $\left({ }^{\circ} \mathrm{C}\right.$, shading) between the 1870-2010 HadISST sea surface temperature anomalies and (a) PC1, (b) PC2, (c) the $E$-index, and (d) the $C$-index. The percentage of explained variance is contoured (the interval is $20 \%(10 \%$ ) below (above) $60 \%$ ).

in contrast to the axes $\mathrm{PC} 1-\mathrm{PC} 2$, which result from the maximization procedure of SST variance explained by these modes.

[12] This same behavior is encountered in two other observational SST estimates (ERSST v3b [Smith et al., 2008] and Kaplan SST v2 [Kaplan et al., 1998]; not shown), but is much clearer in the model data (Figures $2 b-2 d$ ), which contain a substantially larger number of extraordinary warm events. The fact that even Zebiak and Cane's [1987] ICM is able to depict this behavior indicates that it is not essential to invoke mechanisms external to the tropical Pacific to explain the different regimes, although we do not rule out their role as drivers [e.g., Vimont et al., 2001].

[13] The spatial patterns of SST associated with the EOFs (Figures $3 \mathrm{a}$ and $3 \mathrm{~b}$ ) are similar to the ones reported by Ashok et al. [2007], although our second mode does not show the signal in the far-western tropical Pacific seen in their "Modoki" pattern due to a more equatorially-confined domain. Using the domain of Ashok et al. [2007] and the slightly longer time period used in this study yields patterns essentially the same as theirs, but a long period (1950-2009) yields a second EOF mode that lacks the negative loadings in the western Pacific, similar to the ones obtained in this study. The first mode (Figure 3a) explains most of the variance in the Niño 3 region whereas the second mode (Figure 3b) explains up to $40 \%$ in the Niño 4 region with weak loadings of opposite sign around the Niño $1+2$ region. The corresponding patterns in the climate models (not shown) are qualitatively similar.

[14] The SST patterns associated with the $E$ and $C$ indices, on the other hand, are both ENSO-like (Figures $3 \mathrm{c}$ and $3 \mathrm{~d}$ ). The $E$ pattern has its strongest amplitude and explained variance along the eastern equatorial Pacific (east of $120^{\circ} \mathrm{W}$ ) and along the coast of Peru (Figure 3c), whereas the $C$ pattern has its amplitude and explained variance in the central equatorial Pacific $\left(170^{\circ} \mathrm{E}-100^{\circ} \mathrm{W}\right.$, maximum in the Niño 4 region; Figure 3d).

[15] Since extraordinarily warm and strongly cold events belong to different regimes, their SST patterns are different. In particular, the $C$ pattern (Figure 3d), is similar to the pattern obtained by compositing warm and cold events and averaging the patterns [Hoerling et al., 1997, Figure 7c], while the $E$ pattern (Figure 3c), describes the difference between them [Hoerling et al., 1997, Figure 7d]. This is reflected by the positive (negative) skewness of $1.78(-0.62)$ for the $E(C)$ index.

[16] The $E$ and the $C$ patterns are also similar to Rasmusson and Carpenter's [1982] composite SST anomalies for the "peak" and the subsequent "mature" phases, respectively, of the evolution of the composite warm El Niño event. In this "canonical" El Niño, the event starts near the positive $E$ axis,
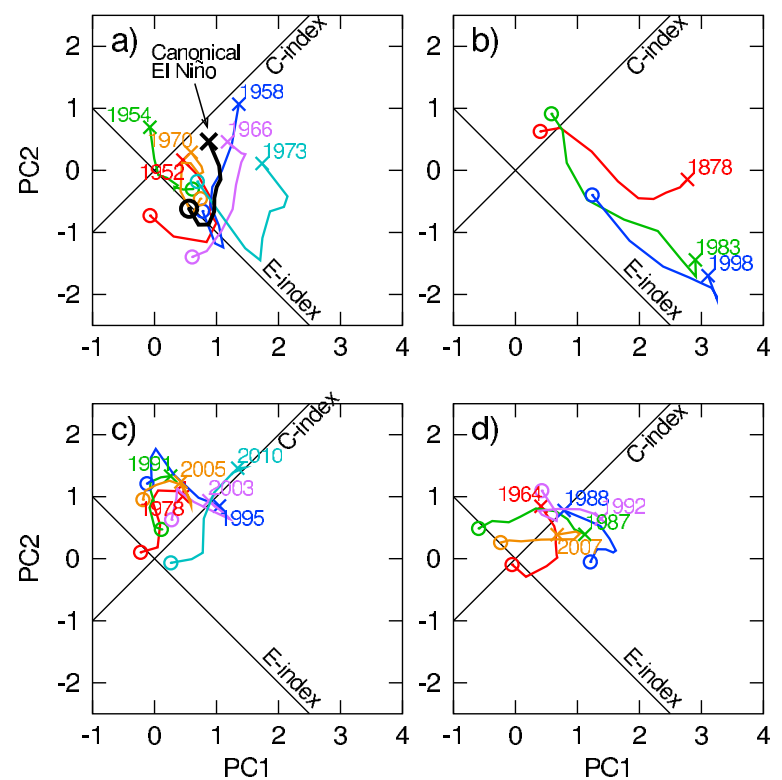

Figure 4. Evolution of $\mathrm{PC} 1$ and $\mathrm{PC} 2$ from May (indicated with circles) to the following January (crosses, corresponding year shown) El Niño events: (a) events considered by Rasmusson and Carpenter [1982] (their composite is shown thicker); (b) extraordinary events; (c) central Pacific events [Kug et al., 2009] including the recent 2009-10 event [Lee and McPhaden, 2010]; (d) other moderate events since 1950 according to NOAA, corresponding to DJF Oceanic Niño Index $\geq 1{ }^{\circ} \mathrm{C}$ (see http://www.cpc.noaa.gov/products/ analysis_monitoring/ensostuff/ensoyears.shtml for details). 
with warming off Peru between April and July, and then evolves towards the positive $C$ axis, with warming in the central equatorial Pacific in the austral summer, as shown in Figure 4a.

[17] On the other hand the extraordinary $1877-78,1982$ 83, and 1997-98 warm events started with positive $C$ index values and then strongly developed towards positive $E$ index values (Figure 4b). Thus, the warming in the equatorial Pacific and along the coast of Peru was much stronger and took place later along the evolution of the event compared to the canonical El Niño. The transition to normal/cold conditions on the $C$-index axis takes place only during the April-September period, within the positive E/negative $C$ quadrant (Figure 2a).

[18] The "Central Pacific" El Niño events [Kug et al., 2009] go through a negative $E$ phase during austral winter (Figure 4c), except for the strong 2009-10 event. Their states in austral summer are clustered around the positive $C$ axis, close to several of those of "canonical" events (Figure 4a) and other moderately warm events (Figure 4d), but far from the extraordinary warm events (Figure $4 b$ ). Hence, during austral summer, the moderate El Niño events, including the "Modoki" or "Central Pacific" events, can be considered part of a single category distinct from the extraordinary warm events.

\section{Discussion and Conclusions}

[19] Trenberth and Stepaniak [2001] recognized that at least two degrees of freedom are needed to describe ENSO evolution and the differences between events, and suggested that the TNI and Niño 3.4 indices would serve this purpose. On the other hand, Ashok et al. [2007] argued that the first and second EOF modes of the tropical Pacific SST anomalies, closely related to the Niño 3.4 index and TNI, respectively, actually describe two separate phenomenon, as the two indices evolve differently during the so-called "El Niño Modoki" events and during the canonical El Niño [Rasmusson and Carpenter, 1982]. However, the change in phasing in the mid 1970s [Trenberth and Stepaniak, 2001], a key argument for the case that "El Niño Modoki" is a phenomenon distinct from ENSO [Ashok et al., 2007], is mainly due to the extraordinary 1982-83 and 1997-98 El Niño events and not to the Modoki-type events (this was verified by recalculating the lagged correlations after setting both indices to zero for the periods 1982-83 and 1997-98; Figure AM1 of Text S1 of the auxiliary material). ${ }^{1}$ On the other hand, other warm events in this period have not conformed to the "canonical" evolution, while cold events have [McPhaden and Zhang, 2009]. Our equatorial EOF2 also projects onto the Pacific meridional mode of Chiang and Vimont [2004], which explains the nonlinear relation of the latter and ENSO.

[20] Here we define two indices, the $E$ and $C$ indices, that are by construction independent (i.e., uncorrelated) and that best depict the complexity of ENSO, respectively describing the regimes that account for a) extreme warm events and b) ordinary cold and moderately warm events. The $C$ index is the one that best relates to the so-called "El Niño Modoki", although its pattern shares many characteristics with the canonical El Niño of Rasmusson and Carpenter [1982].

\footnotetext{
${ }^{1}$ Auxiliary materials are available in the HTML. doi:10.1029/ 2011GL047364.
}

[21] The regime of extreme warm events is illustrated in nature by the 1982-83 and 1997-98 events and, to a lesser extent, by the 1877-78 event. Focusing the study of ENSO towards this extreme regime suggests that El Niño is episodic rather than cyclic [Kessler, 2002] and theoretical work along this line has led to simple models that produce a bursting behavior and asymmetry [Timmermann et al., 2003; Schopf and Burgman, 2006; Boucharel et al., 2009]. However, the perspective of an episodic El Niño does not consider the moderate regime, and neither do the simple models based on this view. On the other hand, that Zebiak and Cane's [1987] model reproduces some aspects of the two regimes suggests that more adequate simple models could be developed to account for the peculiarities of both types of events. It is important to note that these models require at least three degrees of freedom to reproduce the bursting behavior, so for modeling or forecasting purposes, another independent parameter (e.g., associated with subsurface temperature) is needed in addition to the $C$ and $E$ indices.

[22] We note that the austral summer SST anomaly patterns during moderate warm events (both canonical and Modoki) are quite similar to that associated with positive $C$ index. Canonical and Modoki events differ mainly in the austral winter, notably with the lack of the precursor warming off Peru in the case of the "El Niño Modoki" [Ashok et al., 2007]. Cane [1983] noted in relation to the extraordinary 1982-83 event, such a "first phase of the typical El Niño is not essential". Its absence does not imply necessarily a different kind of phenomenon. On the other hand, there is evidence that suggests that the variability off Peru can significantly affect the basin-wide dynamics [Toniazzo, 2010], so its importance can not yet be dismissed. It is interesting to note that the 2009-10 event, perhaps the strongest event on record in the central Pacific [Lee and McPhaden, 2010], presented a small precursor warming off the Peruvian coast (Figure 4c), in contrast to the Modoki-type events.

[23] Lee and McPhaden [2010] show a positive trend in Niño 4 SST peaks during El Niño events and argue that this drives the overall warming in this region. However, the contribution of warm events to this trend is sensitive to what time of the year is considered and only during the last third of the calendar year do warm conditions present a substantially larger trend than neutral conditions (Figure AM2 of Text S1), suggesting that El Niño is perhaps only partly responsible for the warming. Nevertheless, we also find that $C$ (closely related to Niño 4; equation (3)) has a positive trend in its variability (Figure AM3b of Text S1) as well as in the mean (Figure AM3a of Text S1) after 1950, but its skewness shows a trend towards more negative values, suggesting an increase in the intensity of cold events, consistent with the trend during cold ENSO conditions that is negative relative to that during neutral conditions (Figure AM2 of Text S1). With respect to $E$, there is a negative trend in the variability associated with cold and moderately warm events (i.e., the extreme 1982-83 and 1997-98 events are removed first) (Figures AM3b and AM3c of Text S1), which takes place mainly during the austral winter (not shown), consistent with the disappearance of the precursor warming off South America. The combination of these trends in the cold and moderately warm regime indicates to a shift in variability towards the central Pacific, with stronger cold events in this region.

[24] This appears consistent with projections of future changes in ENSO [e.g., Yeh et al., 2009], but we argue that 
unless the models can reproduce both cold/moderately warm and extreme warm regimes, the projections will be incomplete, at best. In particular, despite some advances on this issue [e.g., Wang and An, 2001; Kim and An, 2011], the controls on the likelihood of the occurrence of extreme warm events are not well understood and, considering that climate models are still generally deficient in the far eastern Pacific [Bretherton, 2007] and that this area could significantly influence the rest of the basin [Toniazzo, 2010], it seems likely that our projections related to extreme warm events will suffer accordingly.

[25] Acknowledgments. The authors thank two anonymous reviewers for their suggestions. Partial funding for this study was provided by the IRD LMI "Dinámica del Sistema de la Corriente de Humboldt". KT and AM were partially supported by Comisión Nacional de Investigación Científica y Tecnológica (CONICYT) -Chile through grant Fondecyt 1080058. KG was supported by CNES (Centre National d'Etudes Spatiales, France). The HadISST, ERSST and Kaplan SST datasets were downloaded from the Hadley Centre, NOAA/OAR/ESRL PSD and IRI/LDEO Climate Data Library websites, respectively. The GFDL CM2.1 data was obtained from the PCMDI CMIP3 website. Figures and calculations were made with the GNU Octave and GrADS software.

[26] Editor thanks the two anonymous reviewers for their assistance in evaluating this paper.

\section{References}

Ashok, K., S. K. Behera, S. A. Rao, H. Weng, and T. Yamagata (2007), El Niño Modoki and its possible teleconnection, J. Geophys. Res., 112, C11007, doi:10.1029/2006JC003798.

Boucharel, J., B. Dewitte, B. Garel, and Y. duPenhoat (2009), ENSO's non-stationary and non-Gaussian character: The role of climate shifts, Nonlinear Processes Geophys., 16, 453-473.

Bretherton, C. S. (2007), Challenges in numerical modeling of tropical circulations, in The Global Circulation of the Atmosphere, pp. 302-330, Princeton Univ. Press, Princeton, N. J.

Cane, M. (1983), Oceanographic events during El Niño, Science, 222(4629), 1189-1195.

Chiang, J., and D. Vimont (2004), Analogous Pacific and Atlantic meridional modes of tropical atmosphere-ocean variability, J. Clim., 17, 4143-4158.

Dewitte, B. (2000), Sensitivity of an intermediate coupled oceanatmosphere model of the tropical Pacific to its oceanic vertical structure, J. Clim., 13, 2363-2388.

Dewitte, B., and D. Gushchina (2010), A mechanism of ENSO modulation in a tropical ocean-atmosphere hybrid coupled model, in Climate Variability in the Tropical Pacific: Mechanisms, Modeling and Observations, edited by Y. duPenhoat and A. V. Kislov, pp. 96-110, MAKS, Moscow. Hoerling, M., A. Kumar, and M. Zhong (1997), El Niño, La Niña, and the nonlinearity of their teleconnections, J. Clim., 10, 1769-1786.

Kao, H.-Y., and J.-Y. Yu (2009), Constrasting eastern-Pacific and central Pacific types of ENSO, J. Clim., 22, 615-632.

Kaplan, A., M. A. Cane, Y. Kushnir, A. C. Clement, M. B. Blumenthal, and B. Rajagopalan (1998), Analyses of global sea surface temperature 1856-1991, J. Geophys. Res., 103, 18,567-18,589.

Kessler, W. S. (2002), Is ENSO a cycle or a series of events?, Geophys. Res. Lett., 29(23), 2125, doi:10.1029/2002GL015924.

Kim, B.-M., and S.-I. An (2011), Understanding ENSO regime behaviour upon an increase in the warm-pool temperature using a simple ENSO model, J. Clim., 24, 1438-1450, doi:10.1175/2010JCLI3635.1.

Kug, J.-S., F.-F. Jin, and S.-I. An (2009), Two types of El Niño events: Cold tongue El Niño and warm pool El Niño, J. Clim., 22, 1499-1515.
Kug, J.-S., J. Choi, S.-I. An, F.-F. Jin, and A.-T. Wittenberg (2010), Warm pool and cold tongue El Niño events as simulated by the GFDL2.1 coupled GCM, J. Clim., 23, 1226-1239.

Larkin, N. K., and D. E. Harrison (2002), ENSO warm (El Niño) and cold (La Niña) event life cycles: Ocean surface anomaly patterns, their symmetries, asymmetries, and implications, J. Clim., 15, 1118-1140.

Larkin, N. K., and D. E. Harrison (2005), Global seasonal temperature and precipitation anomalies during El Niño autumn and winter, Geophys. Res. Lett., 32, L16705, doi:10.1029/2005GL022860.

Lee, T., and M. J. McPhaden (2010), Increasing intensity of El Niño in the central-equatorial Pacific, Geophys. Res. Lett., 37, L14603, doi:10.1029/ 2010 GL044007.

McPhaden, M. J., and X. Zhang (2009), Asymmetry in zonal phase propagation of ENSO sea surface temperature anomalies, Geophys. Res. Lett., 36, L13703, doi:10.1029/2009GL038774.

Neelin, J. D., and N. Zeng (2000), A quasi-equilibrium tropical circulation model-formulation, J. Atmos. Sci., 57, 1741-1766.

Rasmusson, E. M., and T. H. Carpenter (1982), Variations in tropical sea surface temperature and surface wind fields associated with the Southern Oscillation/El Niño, Mon. Weather Rev., 110, 354-384.

Rayner, N. A., D. E. Parker, E. B. Horton, C. K. Folland, L. V. Alexander, D. P. Rowell, E. C. Kent, and A. Kaplan (2003), Global analyses of sea surface temperature, sea ice, and night marine air temperature since the late nineteenth century, J. Geophys. Res., 108(D14), 4407, doi:10.1029/ 2002JD002670.

Schopf, P. S., and R. J. Burgman (2006), A simple mechanism for ENSO residuals and asymmetry, J. Clim., 19, 3167-3179.

Smith, T. M., R. W. Reynolds, T. C. Peterson, and J. Lawrimore (2008), Improvements to NOAA's historical merged land-ocean surface temperature analysis (1880-2006), J. Clim., 21, 2283-2296.

Timmermann, A., F.-F. Jin, and J. Abshagen (2003), A nonlinear theory for El Niño bursting, J. Atmos. Sci., 60, 152-165.

Toniazzo, T. (2010), Climate variability in the south-eastern tropical Pacific and its relation with ENSO: A GCM study, Clim. Dyn., 34, 1093-1114.

Trenberth, K., and D. Stepaniak (2001), Indices of El Niño evolution, J. Clim., 14, 1697-1701.

Vimont, D. J., D. S. Battisti, and A. C. Hirst (2001), Footprinting: A seasonal connection between the tropics and mid-latitudes, Geophys. Res. Lett., 28, 3923-3926.

Wang, B., and S. An (2001), Why the properties of El Niõ changed during the late 1970s, Geophys. Res. Lett., 28, 3709-3712.

Weng, H., K. Ashok, S. K. Behera, S. A. Rao, and T. Yamagata (2007), Impacts of recent El Niño Modoki on dry/wet conditions in the Pacific rim during boreal summer, Clim. Dyn., 29, 113-129.

Wittenberg, A. T., A. Rosati, N. C. Lau, and J. J. Ploshay (2006), GFDL's CM2 global coupled climate models. Part III: Tropical Pacific climate and ENSO, J. Clim., 19, 698-722.

Wyrtki, K. (1975), El Niño-The dynamic response of the equatorial Pacific Ocean to atmospheric forcing, J. Phys. Oceanogr., 5, 572-594.

Yeh, S.-W., J.-S. Kug, B. Dewitte, M.-H. Kwon, B. P. Kirtman, and F.-F. Jin (2009), El Niño in a changing climate, Nature, 461, 511-515.

Yu, J.-Y., and S. T. Kim (2010), Three evolution patterns of CentralPacific El Niño, Geophys. Res. Lett., 37, L08706, doi:10.1029/ 2010GL042810.

Zebiak, S. E., and M. A. Cane (1987), A model of El Niño-Southern Oscillation, Mon. Weather Rev., 115, 2262-2278.

Zeng, N., J. D. Neelin, and C. Chou (2000), A quasi-equilibrium tropical circulation model: Implementation and simulation, J. Atmos. Sci., 57, $1767-1796$.

B. Dewitte and K. Goubanova, Laboratoire d'Etudes en Géophysique et Océanographie Spatiale, CNES/CNRS/IRD/UPS, 18, Av. Edouard Belin, F-31401 Toulouse CEDEX 09, France.

A. Montecinos, Departamento de Geofísica, Universidad de Concepción, Barrio Universitario s/n, Casilla 160-C, Concepción, Chile.

K. Takahashi, Instituto Geofísico del Perú, Calle Badajoz 169, Lima, Perú. (ken.takahashi@igp.gob.pe) 